\title{
Application of Cellular Material in Crashworthiness Applications: An Overview
}

\author{
Ahmad Baroutaji ${ }^{1}$, Arun Arjunan ${ }^{1}$, Abbas Niknejad ${ }^{2}$, TrongNhan Tran ${ }^{3,4}$, Abdul-Ghani \\ Olabi $^{5,6}$
}

(1)- School of Engineering, Faculty of Science and Engineering, University of Wolverhampton, Telford, United Kingdom, TF2 9NT

(2)- Mechanical Engineering Department, Yasouj University, Yasouj, Iran

(3)- Division of Computational Mechatronics, Institute for Computational Science, Ton Duc Thang University, Ho Chi Minh City, Vietnam.

(4)- Faculty of Electrical \& Electronics Engineering, Ton Duc Thang University, Ho Chi Minh City, Vietnam

(5)- Dept. of Sustainable and Renewable Energy Engineering, University of Sharjah, P.O. Box 27272, Sharjah, UAE

(6)- School of Engineering and Applied Science, Aston University, Aston Triangle, Birmingham B4 7ET, UK

\begin{abstract}
Cellular foams are a modern class of materials with unique mechanical properties that have wide ranging engineering applications, in the areas of biomedical, acoustic and thermal insulation, and crashworthiness. Recently, foam materials have received increased attention for vehicle crashworthiness due to their lightweight and excellent energy absorption capabilities that allow significant weight reduction without compromising structural safety aspects. Accordingly, this paper reviews the crush and energy absorption behaviour of foam-filled structures that can be used for crashworthy design in transport engineering. In addition, the mechanical and dynamic properties of cellular material and their role on the crashworthiness performance of filled structure are discussed. Particularly, the influences of foam density and interactions, between the foam and the tubes, on the deformation mode of the filled structures are clarified. The advantages offered by the innovative foam material, which contains a density gradient, on the crashworthiness behaviour are also highlighted. Also, a brief summary of optimisation studies involving the use of foam-filled structures are presented. It was found that the cellular materials improve the crashworthiness performance when they are used as filler material in thin-walled energy absorbers due to their capability of altering the deformation mode to a more favourable one.
\end{abstract}


Keywords: Thin-walled structures, crashworthiness, impact loading, foam, optimisation, functionally graded foam.

\section{Introduction}

Thin-walled energy absorbers received wide applications in railway, aerospace and automotive industries due to their low cost and excellent performance under impact loading [1]. These components collapse progressively when they are subjected to impact loading, absorbing the kinetic energy of the moving mass and converting it into plastic strains energy. The thin-walled tubes showed excellent energy absorption performance under the various types loading including axial loading [2], [3], lateral loading [4]-[10], oblique loading [11], and bending loading [12], [13]. However, with the increased demand to develop light-weight vehicles that consume less fuel and cause reduced air pollution, automotive engineers needed to develop structures that are lightweight without compromising their crashworthiness performance.

One strategy to achieve this is to use lightweight foam materials as fillers in the protecting structures such as thin-walled tubes used at front, side, and rear of a vehicle. These fillers can enhance the energy absorbing behaviour through their favourable crushing response as well as their interactions with the tube material that results in a better deformation pattern of the filled tube compared to its in comparison to empty counterparts. The high strength to weight ratio of the foam-filled structures makes them attractive for mobile engineering applications such as passenger vehicles.

Foam materials have received widespread applications in the transportation industry for crashworthiness and thermal and acoustic insulation [14]-[17], [18]. While polymeric foams have been applied for many years, the focus has been turned towards foam metals in recent years [18]. Metallic and polymeric foam materials have received increased attention as a new generation of 
lightweight materials with high potential for enhancing the energy absorption characteristics and stabilising the crush response of thin-walled structures.

The aim of this paper is to review the crashworthiness performance of foam-filled structures under different types of loadings considering their importance for the structural frames of different types of passenger vehicle. The paper starts with an overview of the mechanical and dynamic features of cellular materials in addition to discussing the main indictors that can be used to evaluate the crashworthiness of such materials. This is followed by the crush and energy absorbing behaviour of foam-filled structures. A summary of crashworthiness optimisation investigations on foam-filled structures is introduced in the latter section. Finally, conclusions and future prospects of foam-filled structures for crashworthiness applications are reported.

\section{Crashworthiness of cellular material}

The mechanical and microstructural properties of a cellular material play an important role in its response to crush forces. Accordingly, this section presents the key properties of cellular materials in addition to the relevant metrices associated with crashworthiness.

\subsection{Mechanical and dynamic characterises of cellular material}

Foam materials are generally featured by high strength to weight ratio as well as excellent acoustic and thermal insulation properties compared with other engineering materials. Foams can be classified into three main types including two dimensional (2D) honeycombs, three dimensional (3D) with open cell configuration, and 3D with closed cell configuration, as shown in Figure 1. The cells in the open-cell foams are connected by struts and the cell walls are broken as such a fluid may pass through the cells. On the other hand, the cells in the closed-cell foams are fully enclosed with cell walls so that a fluid flow is obstructed [19]. The closed-cell configuration is generally stronger than the open cell one. 
The mechanical response of foam material depends upon the cell microstructure including cell size and cell topology, properties of the bulk material, and the relative density of the foam material [20]. The relative density of the foam material $\left(\rho^{*}\right)$ is given by equation (1):

$$
\rho^{*}=\frac{\rho}{\rho_{B}}
$$

Where $\rho_{\mathrm{B}}$ and $\rho$ are the densities of the bulk material associated with cell wall and foam respectively. Generally, the foam material with greater relative density shows greater mechanical strength and this can be attributed to the higher bulk material within the foam [21].

The influence of cell microstructure on the behaviour of foam materials is due to the fact that the deformation mechanism of foam material at cell level is governed by bending and stretching of cell wall followed by buckling and tearing in post-yield stage [22]. The cell wall bending strength is affected by the cell size where the smaller cell size exhibits higher strength due to increasing strength of cell edges [23]. Since the mechanical behaviour of cellular materials is influenced by the cell microstructure, the morphological imperfections in cell microstructure such as nonuniform cell wall thickness, cell-size variations, fractured cell walls, cell-wall misalignments, and missing cells have a significant effect on the mechanical behaviour of the metallic foams [24]. Foam materials are generally not used for applications where tension and shear loading are dominant. However, they are usually used where compression loads are expected. The most attractive feature of foams is the ability to undergo a large strain deformation while maintaining a low constant stress level before the densification region [22]. A typical compressive stress-strain response of a foam material, as shown in Figure 3, consists of an elastic region, a plateau region where the stress increases slowly as the cells deform plastically, and a densification region where the load increases rapidly as the cell edges progressively touch each other and the material attains bulk-like properties.

The most common mechanical properties of the foam materials are the plateau stress $\left(\sigma_{\mathrm{P}}\right)$, elastic modulus (E), yield point, and the densification strain.

The plateau stress $\left(\sigma_{\mathrm{P}}\right)$ is a function of the foam's relative density and it is given by equation (2): 


$$
\sigma_{P}=C\left(\rho^{*}\right)^{m}
$$

Where coefficients $\mathrm{C}$ and $\mathrm{m}$ are material parameters.

The elastic modulus (E) can be obtained as the slope of the initial loading portion of the curve shown in Figure 3. The densification strain $\left(\varepsilon_{D}\right)$ is the strain at which the foam is completely crushed and there is a sharp increase in the slope of stress-strain curve. The yield stress $\left(\sigma_{Y}\right)$ of the foam material can be obtained using the following equation (3) developed by Reyes at al. [25].

$$
\sigma_{Y}=\sigma_{P}+\gamma \frac{\varepsilon}{\varepsilon_{D}}+\alpha_{2} \ln \left[\frac{1}{1-\left(\frac{\varepsilon}{\varepsilon_{D}}\right)^{\beta}}\right]
$$

Where $\gamma, \alpha_{2}, \varepsilon_{\mathrm{D}}, \beta$ are material parameters and $\varepsilon$ is the equivalent strain.

Amongst the types of foams, metallic and polymeric foam materials were the subject of numerous crashworthiness investigations. Metallic foams can be obtained from different basic metals such as Aluminium (Al), Magnesium $(\mathrm{Mg})$, Copper $(\mathrm{Cu})$, and Titanium (Ti). Compared to other metallic foams, aluminium was the most studied type due to its superior performance and the low relative density which could reach as low as $3 \%$ of the bulk material.

Low-density polymeric (non-metallic) foams have been widely applied for crashworthiness applications in automotive industry due to their excellent energy absorbing capability. They are used as a filler material in bumpers and as reinforcement in roof and door beams to reinforce weak regions of the car structure and improve their responses to impact loading [26]. The main advantage of polymeric foam is that the energy absorption performance is independent of loading direction and thus it is capable of absorbing an oblique impact load very efficiently.

With regards to the dynamic behaviour of foam materials, the dynamic response of cellular material is different to its quasi-static counterpart due to strain rate effect [27]. The strain rate sensitivity of cellular material increases with increased relative density of the cellular material [28]. The macroscopic strain-rate sensitivity of the cellular material may be due to many sources including the strain rate sensitivity of the base material [29], the inertia effects of the individual 
cell walls [30], the contribution of the pressure of the entrapped air in honeycombs [31], and shockwave effects that cause a dynamic localisation of the crushing [30], [32], [33].

\subsection{Evaluation of crashworthiness performance}

There are many indicators or metrics that can be used to evaluate the crashworthiness performance of an energy absorbing structure such as crush efficiency, energy efficiency, specific energy absorption capacity, weight effectiveness and so on. The general approach to calculate these indictors is to conduct a crush test and plot the crush force-displacement response, as shown in Figure 2, which can then be used to extract most of metrics as detailed below.

\subsubsection{Energy absorption capacity $(E)$}

Energy absorption capacity (E) can be measured by calculating the area under the forcedeflection response of an energy absorbing device. It can be defined as the integration of a loaddisplacement curve as shown in equation (4):

$$
E=\int_{0}^{\delta} F(\delta) \cdot d \delta
$$

Where $\mathrm{E}$ is the energy absorption capacity, $\delta$ is the displacement, and $\mathrm{F}(\delta)$ is the loaddisplacement response.

\subsubsection{Specific energy absorption (SEA)}

The specific energy absorption capacity is the most important characteristic of an energy absorber. SEA is defined by energy absorbed per unit mass, and it is given by equation (5):

$$
\mathrm{SEA}=\frac{E}{m}
$$

Where $\mathrm{m}$ is the mass of the energy absorber. SEA is an important energy absorption indictor, particularly in structures where weight is of critical importance. 


\subsubsection{Stroke efficiency $\left(S_{E}\right)$}

The stroke efficiency is defined as the stroke length divided by the original length of the tube. The stroke efficiency can be defined by the equation (6):

$$
S_{E}=\frac{\delta}{L_{o}}
$$

Where $L_{o}$ is the original length of the energy absorber. $S_{E}$ is considered as a good indicator for describing the amount of material that can be used during collapse. This indicator is useful in applications that have restrictions on energy absorber space.

\subsubsection{Mean Crush Force (MCF) and Crush force efficiency (CFE)}

Mean Crush Force $(M C F)$ can be calculated as the ratio between the absorbed energy and the stroke length of the absorbing structure as shown in equation (7):

$$
M C F=\frac{E}{\delta}
$$

Crush Force Efficiency (CFE) is the ratio between the mean crush force and the Peak Crush Force (PCF), which is the maximum load observed in the force-displacement response. CFE can be obtained using equation (8):

$$
C F E=\frac{M C F}{P C F}
$$

\subsubsection{Energy efficiency $\left(e_{E}\right)$}

The energy efficiency indictor is given by equation (9):

$$
e_{E}=\frac{E}{\mathrm{PCF} * L_{o}}=\frac{M C F \times \delta}{P C F \times l_{o}}=C F E \times S_{E}
$$

It is recommended to maximise the energy efficiency of an energy absorber. Ideally, to achieve the maximum value of $e_{E}$, the force-displacement response of the energy absorber should be a rectangle response. 


\subsubsection{Work effectiveness $\left(W_{\text {eff }}\right)$}

The work effectiveness is a combination of the specific energy absorption capacity and the crush efficiency indicator, and it is defined using equation (10):

$$
W_{e f f}=S E A \times S_{E}
$$

This indicator is a useful one, particularly in structures that are restricted in terms of both weight and space as in small cars.

\subsubsection{Dynamic amplification factor (DAF)}

The dynamic amplification factor can be defined as the ratio between the energy absorbed under dynamic loading and the energy absorbed under quasi-static loading up to a given crush distance, and is given by equation (11):

$$
\mathrm{DAF}=\frac{E_{d}}{E_{s}}
$$

DAF is used to assess the effect of dynamic loading on the energy absorption behaviour of the structure.

\section{Crush performance of Foam-Filled thin-walled structures}

In vehicle applications where a high level of energy needs to be dissipated during a crash scenario, the foam material is not used on its own instead it is employed as a filler material to enhance the energy absorption capability. Generally, the loading direction plays an important role in the crush behaviour of the foam-filled structures. A filled structure can be crushed in one of the following loading directions: axial, oblique, lateral and bending loading.

\subsection{Axial Loading}

The early investigations of foam filled thin-walled tubes were performed by Reid et al. [34], [35] in which polyurethane foam was used as a filler material in square, rectangular and tapered tubes subjected to dynamic and quasi-static axial loading. Extensive research has been performed to study the energy absorbing behaviour of axially loaded foam-filled tubes with different shapes, as 
shown in Figure 4, including Square tubes [36], [37], [38], [39], hexagonal and octagonal tubes [38], circular tubes [40], [41], [42], [43], tapered rectangular tubes [44], conical tubes [45]-[47], and hat sections [48]; [49], [50].

Thornton [51] used polyurethane foam as a filler material. Many compression tests were performed in order to investigate the effects of polyurethane foam-filling on the behaviour of metallic tubes. It was found that polyurethane foam-filled structure is not weight-effective unless relatively thin tubes made of low-strength high-density material are used. Similar conclusions were reported by Lampinen and Jeryan [52]. They found that weight effectiveness tends to be reduced when the wall thickness of a polyurethane foam-filled tube is decreased below a certain value. So it was reported that greater weight efficiency can be obtained by using thicker columns rather than using polymer foam fillings. In contrast to the above findings, Reyes et al. [25], Banhart [53], and Santosa et al. [37] reported that filling a tube with aluminium foam provides higher weight efficiency and greater energy absorption than increasing the tube thickness. Furthermore, Hanssen et al. [54] found that using aluminium foam along with a thin-walled tube reduces the length and volume of the tube by $32 \%$ and $68 \%$, respectively; which is important for the design of energy absorbing systems. Foam-filling is preferred to thickening the tube wall, since increasing the thickness increases the mass and decreases the weight efficiency of the energy absorber.

Abedi et al. [55] investigated experimentally axial folding process of simple and grooved tubes with circular cross-section in two different conditions of empty and polyurethane foam-filled. They demonstrated that increment of absorbed energy due to the foam-filler in the grooved tubes is more than the corresponding value in the simple specimens. Also, Niknejad et al. [56] analyzed folding process of circular grooved tubes of empty and foam-filled conditions, by the theoretical and experimental methods. In the theory, they considered the interaction factor of the polyurethane foam and grooved tubes equal to 2 . On the other hand, they showed that the 
absorbed energy due to the interaction effect is equal to the absorbed energy by the polyurethane foam.

There are two significant changes that can be observed in the collapse behaviour of foam filled tubes; firstly, it increases the number of lobes, and secondly it shortens the fold length. Hanssen et al. [36] noticed that the number of lobes increased with increasing foam density as shown in Figure 5. The author reported that the presence of foam filler produced more resistance to inward bending and thus the plastic fold length reduced and the number of folds increased. Similar observation was reported by Asavavisithchai et al. [57] who founded that the collapse mode of a foam filled tube is a compact mode. Also, it was found that the diamond deformation mode in an empty circular tube alter to a concertina mode in a foam-filled tube, regardless of the foam type and density [36], [57] as shown in Figure 6. These changes in deformation mode of foam filled tubes are mainly due to the interaction effects between the thin-walled tube and the filler material [19]. Toksoy and Guden [42] reported that the interaction effects in the foam-filled components are attributed to two reasons; first, the resistance of the filler material to the outward and inward folding of the tube during the progressive axial collapse and second, the interfacial friction stress between the filler material and the tube wall. The interaction effects were further explained by Zarei and Kroger [39], who investigated the collapse and energy absorption responses of foamfilled square tubes. The authors reported that due to interaction effects, the crush force of the foam-filled tube was higher than the sum of the crush forces of empty tube and foam when crushed separately (Figure 7).

The energy absorption of foam filled tubes is mainly related to the density of the foam, where structures with higher foam density have higher energy absorption [44], [58]. Mirfendereski et al. [44] reported that the foam density has an insignificant effect on the initial peak load of tapered tube but it has an important effect on other energy absorption parameters such as the absorbed energy, the mean load, and the crush force efficiency which increase as the foam density increases. 
The main drawback of using high-density foams as a filler material is that it may lead to global bending deformation mode [59], [35], [19], [60]. Reid et al. [35] found that using polyurethane foam with a density higher than $320 \mathrm{~kg} \cdot \mathrm{m}^{-3}$ may cause global bending in foam-filled square tubes. Furthermore, increasing the foam density may affect the weight effectiveness of the filled structure. The results obtained by Onsalung et al. [58], who investigated the energy absorption behaviour of a square steel tube filled with polyurethane foam, indicated that a filled tube with a foam density of $200 \mathrm{~kg} \cdot \mathrm{m}^{-3}$ offers higher SEA than a tube with a density of $300 \mathrm{~kg} \cdot \mathrm{m}^{-3}$. Seitzberger et al. [59] noticed that using an aluminium foam with a density of $700 \mathrm{~kg} . \mathrm{m}^{-3}$ in foam filled circular tubes can cause global bending, as shown in Figure 8. In order to avoid this undesirable feature, the authors suggested that using foam density of lower than $600 \mathrm{~kg} \cdot \mathrm{m}^{-3}$ may prevent global bending characteristics in foam-filled circular tubes.

\subsection{Oblique loading}

The performance of foam-filled tubes was evaluated under oblique loading in many studies [45], [61], [62]. Borvik et al. [40] and Reyes et al. [63] have examined aluminium foam-filled square and circular tubes under oblique loads. Both authors have reported that both PCF and MCF of foam-filled tubes decrease with increasing the load angle. The effects of impactor inclination and foam density on the crashworthiness of metal foam-filled tubes were investigated by Shahbeyk et al. [64]. It was reported that high and medium-density foam-filled tubes undergo a global bending mode under a slightly inclined impactor.

The tapered tubes can be considered as a solution for an unstable crush mode in the case of foamfilled sections loaded obliquely [45]. Experimental investigations on the dynamic and quasi-static responses of tapered rectangular tubes filled with polyurethane foam have been carried out by Reid et al. [35]. It was noticed that the presence of foam prevents global bending and reduces the magnitude of the load amplitude. The author also found that mean load increased as the crush progressed under impact loading. Mirfendereski et al. [44] examined the collapse and energy absorbing response of empty and polyurethane foam-filled tapered rectangular tubes under static 
and dynamic loading. It was found that the foam-filled tapered tubes had enhanced energy absorption performance where a tapered tube with four tapered sides (frusta) had the smallest PCF in both dynamic and static loadings. The results showed that with increasing the number of tapered sides, the crush efficiency was increased but the specific absorbed energy was decreased. Ahmad et al. [45] examined the energy absorbing responses of empty and polyurethane foamfilled conical tubes under oblique impact loading. The authors found that foam-filled conical tubes were effective energy absorbers because they can absorb both oblique and axial impact loads and they have a less tendency to undergo a global bending deformation mode.

\subsection{Lateral flattening}

The crashworthiness of various foam-filled thin-walled structures under lateral loading, as shown in Figure 9, was reported in literature [7], [10], [65]-[67].

Niknejad et al. [66] performed an experimental study on the lateral crushing of brazen circular tubes filled with polyurethane foam under quasi-static loading. The effects of geometrical factors and foam-filling on the energy absorbing responses were reported. The experimental results revealed that using the polyurethane foam enhances energy absorption properties of the circular tubes under lateral loading; where the foam filled tubes exhibit higher energy absorption than the empty ones.

Niknejad and Rahmani [67] studied the lateral compression of hexagonal columns. Empty and polyurethane foam-filled tubes manufactured from a brass alloy, steel, and galvanized iron materials were tested under quasi-static lateral loading. Theoretical relations that describe the lateral collapse load as a function of geometrical and material parameters were developed. It was found that the lateral load of the tube is proportional to the plateau stress of the foam material and the length of the tube.

Fan et al. [68] conducted experimental and numerical investigations on the lateral compression of sandwich tubes made of aluminium alloy and ALPORAS® aluminium foam core. A set of sandwich tubes with different diameter to thickness ratios were crushed in this study. Three types 
of deformation mechanisms were observed in the lateral collapse of sandwich tubes including sequential collapse pattern, simultaneous collapse pattern, and simultaneous collapse pattern with facture of the foam core. The numerical and experimental results showed that using sandwich tubes as energy absorbers enhanced the energy absorption and the crush strength. In their second paper, Fan et al. [69] numerically and experimentally investigated the behaviour of sandwich structures under dynamic lateral loading. The sandwich structures under dynamic loading exhibited the same deformation modes as those observed in the case of quasi-static loading. The authors found that there is a critical impact velocity under which a sandwich tube absorbs the same amount of energy as in quasi-static loading. When an impact velocity higher than the critical is used, the sandwich tube absorbs a greater amount of energy than that absorbed in the quasi-static case.

Niknejad and Orojloo [70] examined the crashworthiness behavior of empty and foam-filled nested tubes energy absorber. Experimental investigations were performed to explore effects of loading angle, polyurethane foam-filler, material type and thickness of the inner tube and nesting arrangement on the response of this energy absorber. The obtained results indicated that a design with foam filling, as shown in Figure 9 (d), is the one which has the highest SEA.

\subsection{Lateral bending}

Automobile structural frame contains many structural elements that could be subjected to bending during different crash scenarios. Accordingly, enhancing the bending performance of such structures using foam-filling method was the subject of many investigations. The bending collapse of foam-filled thin-walled structures were studied for both square [71], [72] and circular [13], [73] cross sections. Figure 10 illustrate a typical deformation mode of foam-filled tubes under bending loading. Santosa and Wierzbicki [72] studied the effect of using a foam-filler on enhancing the bending collapse behaviour of thin-walled tubes. They have found that filling a square tube with low-density aluminium foam or honeycomb resulted in significantly improved 
bending behaviour. Consequently, it was reported that adopting foam filling as a strengthening method is preferable to increasing the thickness of the tube. Similar findings were reported by Zarei and Kroger [71] who stated that the use of aluminium foam as a filler material increases the bending resistance of the aluminium tubes. Chen [48], who studied the bending collapse of empty and foam filled tubes with hat profiles, also reported that foam filled tube provide an increase of up to $40 \%$ in the SEA compared to empty tubes. Li et al. [73] evaluated the crashworthiness behaviour of foam-filled and empty thin-walled single and double tubes under dynamic bending loading. The authors reported that among the different configurations considered, the foam filled double tube presents the best bending resistance and energy absorption capacity.

The main reason for the energy absorption enhancement in the foam-filled tubes under bending loading is because of the foam core delay the local indentation of the tube by introducing additional support from inside [73]. Also, the interaction effects between the foam core and tube wall make the crushing loads of foam-filled greater than the empty ones [13].

As it can be seen from the studies discussed so far, using foam as filler in a thin-walled tube enhances both the bending strength and the energy absorbing performance. However, the bending deformation mode of the tube may be associated with a tensile failure, as shown in Figure 11, which significantly decrease the energy absorption capability of the structure [13]. The tensile failure depends mainly on the density of the foam core and can be increased by increasing the foam density [13].

\subsection{Advanced Foam-Filled Components}

The recent trends of foam-filled tubes are all about using a new class of foam material that contains a density gradient which is called Functionally Graded Foam (FGF) material.

Functionally Graded Foam (FGF) material was used to enhance the energy absorption behaviour of tubes with different shapes including circular tubes [74], multi-cell square columns [75], square tubes [76], tapered circular tubes [77] under both axial and bending loading conditions. 
Sun et al. [76] investigated the axial crushing behaviour of FGF-filled structures and they reported that FGF material is superior to its uniform counterparts in overall crashworthiness responses. The authors also stated that the gradient parameter plays an important role in the crushing behaviour of such structures. Attia et al. [78] studied the crashworthiness performance of structures filled with FGF with axial and lateral grading patterns as shown in Figure 12. The authors observed that ascending grading pattern yields better energy absorption characteristics than the descending one for both grading configurations. Similar findings were also observed by Zhang el at. [79] who used FGF to fill a circular tube with functionally graded thickness. It was reported that ascending gradient of foam density is recommended for effective energy absorption behaviour.

The FGF material was also used as a filler material for structural components subjected to bending loading. The bending behaviour of FGF-filled tubes was investigated by Fang et al. [80] who found that the FGF tubes exhibit better specific energy absorption (SEA) and crash force efficiency (CFE), but worse maximum impact force (PCF) than uniform foam filled tubes. Sun et al. [81] investigated the impact response of sandwich panels with homogeneous and graded foam cores under bending loading. The authors found that the descending density gradient from the front plate towards the back outperforms other gradient configurations in terms of energy absorption behaviour.

Overall, all the findings reported from investigations on FGF-foam filled structures indicated that FGF material have better crashworthiness behaviour than the ones that feature uniform foam.

In addition to FGF, auxetic foam, which is an advanced type of foam with a negative Poisson's ratio, has been used as a filler material [82]. Mohsenizadeh et al. [82] investigated axial crashworthiness behaviour of auxetic foam-filled aluminium square structures. The tubes filled with auxetic foam were observed to have higher specific energy absorption capacity and better progressive collapse than the empty and polyurethane foam-filled tubes. 


\section{Crashworthiness optimal design of foam-filled structures}

The density of the foam material was reported in many studies to have significant impact on the energy absorption behaviour of the foam-filled structure. Generally, the greater the foam density, the greater the energy absorbed by a foam-filled tube. However, higher foam density means higher mass of the filling material and hence this might compromise the lightweight feature of the foam-filled structure resulting in lower SEA [25]. Additionally, the high foam density may also lead to global bending deformation mode for those foam-filled tubes under axial loading, as discussed in section 3.1. Also, the higher foam density in foam-filled structures under bending tends to fail at lower deflection than those structures filled with lower density [13], as clarified in section 3.4. Thus, selecting a filler material with appropriate density is crucial for successful energy absorption process and this can only be achieved through optimising foam-fillers for the different structures. For this reason, the single and multi-objective design optimisation methods have attracted a lot of studies in recent years to enhance the crashworthiness of foam-filled structures. For example, Zarei and Kroger [83] adopted multi-objective optimisation approach to find the best design of foam-filled aluminium thin-walled tubes that has maximum energy absorption capacity and minimum weight. Yin et al. [77] conducted crashworthiness optimisation design of tapered tubes filled with functionally graded foam using dynamic ensemble metamodel. It was pointed out that employing the dynamic ensemble metamodels in the optimisation algorithm is more feasible than using traditional static ones. Sun et al. [84] used robust optimisation method that considers uncertainties in the design variables to find the optimal design of foam-filled hexagonal tubes. The authors indicated that robust optimisation method can minimise the effects of uncertainties on the design criteria resulting in effective solution for crashworthiness optimisation design problem. Zhang et al. [85] adopted kriging metamodeling technique with the genetic and non-dominated sorting genetic optimisation algorithms to find the optimal design of foam-filled bitubal square tubes. An et al. [86] employed multi-objective particle swarm optimization (MOPSO) algorithm to determine the optimal crashworthiness 
configuration of foam-filled thin-walled tubes with functionally lateral graded thickness. Jianguang et al. [87] sought an optimal crashworthiness design for axially loaded functionally graded foam-filled functionally graded thickness structures using Multiobjective Particle Swarm Optimization (MOPSO) algorithm. In a similar investigation, Jianguang et al. [80] performed multi-objective crashworthiness design of functionally graded foam-filled squared tubes subjected to bending impact loading. In this study, MOPSO algorithm and Kriging modelling technique were used to determine the configurations that improve SEA and reduce PCF.

\section{Conclusion and Future Directions}

Designing a crashworthy structure with excellent energy absorption performance continues to remain hot topic for many industries that are producing passenger vehicles such as railway, aviation and automotive sectors. Over the last forty years, metallic thin-walled structures dominated the crashworthiness studies due to their excellent plastic deformation behaviour. However, with the advancements made in the area of cellular materials, many researchers have started improving the crashworthiness behaviour of the traditional shell structures by filling them with foam material. The current paper reviewed the energy absorption behaviour of such foamfilled structures under different types of loading including axial, oblique, lateral, and bending. The foam-filled structures proved to be a weight-effective solution for achieving a better crashworthiness performance. For all loading directions, the foam-filled structures exhibited higher energy absorption capacity than their empty counterparts. This was due to the interaction effects between the foam material and the thin-walled tubes resulting in better deformation patterns. The crashworthiness performance of such structures can be further improved by using functionally graded foam which is capable for absorbing greater energy without increasing the initial peak crush force.

Generally, aluminium foam was the most used metallic foam material for crashworthiness applications. Consequently, other types of metallic foam such magnesium and nickel have 
received less attention and for this they could be subject of future studies in the area. Also, the majority of researchers working on polymeric foam were focused on polyurethane foam while the other lightweight polymeric foams, such as Expanded Polypropylene (EPP), have only received limited attention despite its superior properties. Therefore, more investigations need to be conducted to understand the full potential of such materials. Other types of foam such as auxetic foam were reported to have better crashworthiness behaviour than the traditional foam. However, the numbers of studies on such foam have been limited making it worthwhile to be considered for further investigations.

\section{References}

[1] A. Baroutaji, M. Sajjia, and A.-G. Olabi, "On the crashworthiness performance of thin-walled energy absorbers: Recent advances and future developments," Thin-Walled Struct., vol. 118, pp. 137-163, Sep. 2017.

[2] Z. Fan, G. Lu, and K. Liu, "Quasi-static axial compression of thin-walled tubes with different cross-sectional shapes,” Eng. Struct., vol. 55, pp. 80-89, Oct. 2013.

[3] X. Zhang and H. Huh, "Crushing analysis of polygonal columns and angle elements," Int. J. Impact Eng., vol. 37, no. 4, pp. 441-451, Apr. 2010.

[4] A. Baroutaji and A.-G. A. G. Olabi, "Analysis of the Effect of the Elliptical Ratio in Tubular Energy Absorbers Under Quasi-Static Conditions," in Advanced Structured Materials, vol. 16, A. Öchsner, L. F. M. da Silva, and H. Altenbach, Eds. Berlin, Heidelberg: Springer Berlin Heidelberg, 2012, pp. 323-336.

[5] A. Baroutaji, M. D. Gilchrist, D. Smyth, and A. G. Olabi, "Crush analysis and multi-objective optimization design for circular tube under quasi-static lateral loading," Thin-Walled Struct., vol. 86, pp. 121-131, 2015.

[6] A. Baroutaji, M. D. Gilchrist, and A. G. Olabi, "Quasi-static, impact and energy absorption of internally nested tubes subjected to lateral loading," Thin-Walled Struct., vol. 98, pp. 337-350, Jan. 2016.

[7] A. Baroutaji, M. D. Gilchrist, D. Smyth, and A. G. Olabi, "Analysis and optimization of sandwich tubes energy absorbers under lateral loading," Int. J. Impact Eng., vol. 82, pp. 7488, Aug. 2015.

[8] A. Baroutaji, E. Morris, and A. G. Olabi, "Quasi-static response and multi-objective crashworthiness optimization of oblong tube under lateral loading," Thin-Walled Struct., vol. 82, pp. 262-277, Sep. 2014.

[9] A. Niknejad, S. M. Elahi, S. A. Elahi, and S. A. Elahi, "Theoretical and experimental study on the flattening deformation of the rectangular brazen and aluminum columns," Arch. Civ. Mech. Eng., vol. 13, no. 4, pp. 449-464, 2013. 
[10] A. Baroutaji and A. G. Olabi, "Lateral collapse of short-length sandwich tubes compressed by different indenters and exposed to external constraints," Materwiss. Werksttech., vol. 45, no. 5, p. n/a-n/a, May 2014.

[11] T. Tran and A. Baroutaji, "Crashworthiness optimal design of multi-cell triangular tubes under axial and oblique impact loading," Eng. Fail. Anal., vol. 93, pp. 241-256, Nov. 2018.

[12] X. Zhang, H. Zhang, and Z. Wang, "Bending collapse of square tubes with variable thickness," Int. J. Mech. Sci., vol. 106, pp. 107-116, Feb. 2016.

[13] I. Duarte, M. Vesenjak, L. Krstulovic-Opara, and L. Krstulovi??-Opara, "Dynamic and quasistatic bending behaviour of thin-walled aluminium tubes filled with aluminium foam," Compos. Struct., vol. 109, no. 1, pp. 48-56, 2014.

[14] A. Arjunan, C. J. Wang, K. Yahiaoui, D. J. Mynors, T. Morgan, and M. English, "Finite element acoustic analysis of a steel stud based double-leaf wall," Build. Environ., vol. 67, 2013.

[15] A. Arjunan, C. J. Wang, K. Yahiaoui, D. J. Mynors, T. Morgan, V. B. Nguyen, and M. English, "Development of a 3D finite element acoustic model to predict the sound reduction index of stud based double-leaf walls," J. Sound Vib., vol. 333, no. 23, 2014.

[16] A. Arjunan, C. Wang, M. English, M. Stanford, and P. Lister, "A computationally-efficient numerical model to characterize the noise behavior of metal-framed walls," Metals (Basel)., vol. 5, no. 3, 2015.

[17] A. Arjunan, "Acoustic Absorption of Passive Destructive Interference Cavities," Mater. Today Commun., Dec. 2018.

[18] J. Baumeister, J. Banhart, and M. Weber, "Aluminium foams for transport industry," Mater. Des., vol. 18, no. 4-6, pp. 217-220, Dec. 1997.

[19] G. Lu and T. X. Yu, Energy Absorption of Structures and Materials. Elsevier, 2003.

[20] A. . Markaki and T. . Clyne, "The effect of cell wall microstructure on the deformation and fracture of aluminium-based foams," Acta Mater., vol. 49, no. 9, pp. 1677-1686, May 2001.

[21] R. Bouix, P. Viot, and J.-L. Lataillade, "Polypropylene foam behaviour under dynamic loadings: Strain rate, density and microstructure effects," Int. J. Impact Eng., vol. 36, no. 2, pp. 329-342, Feb. 2009.

[22] L. J. Gibson and M. F. Ashby, Cellular Solids: Structure and Properties. Cambridge University Press, 1999.

[23] R. Brezny and D. J. Green, "The effect of cell size on the mechanical behavior of cellular materials," Acta Metall. Mater., vol. 38, no. 12, pp. 2517-2526, Dec. 1990.

[24] C. Chen, T. J. Lu, and N. A. Fleck, "Effect of imperfections on the yielding of twodimensional foams," J. Mech. Phys. Solids, vol. 47, no. 11, pp. 2235-2272, Sep. 1999.

[25] A. Reyes, O. S. Hopperstad, A. G. Hanssen, and M. Langseth, "Modeling of material failure in foam-based components," Int. J. Impact Eng., vol. 30, no. 7, pp. 805-834, Aug. 2004.

[26] S. A. Meguid, S. S. Cheon, and N. El-Abbasi, "FE modelling of deformation localization in metallic foams," Finite Elem. Anal. Des., vol. 38, no. 7, pp. 631-643, May 2002.

[27] H. Zhao, I. Elnasri, and S. Abdennadher, "An experimental study on the behaviour under impact loading of metallic cellular materials," Int. J. Mech. Sci., vol. 47, no. 4-5, pp. 757-774, 
Apr. 2005.

[28] F. Yi, Z. Zhu, F. Zu, S. Hu, and P. Yi, "Strain rate effects on the compressive property and the energy-absorbing capacity of aluminum alloy foams," Mater. Charact., vol. 47, no. 5, pp. 417422, Dec. 2001.

[29] V. L. Tagarielli, V. S. Deshpande, and N. A. Fleck, "The high strain rate response of PVC foams and end-grain balsa wood," Compos. Part B Eng., vol. 39, no. 1, pp. 83-91, Jan. 2008.

[30] P. J. Tan, S. R. Reid, J. J. Harrigan, Z. Zou, and S. Li, "Dynamic compressive strength properties of aluminium foams. Part I-experimental data and observations," J. Mech. Phys. Solids, vol. 53, no. 10, pp. 2174-2205, Oct. 2005.

[31] S. Xu, D. Ruan, and G. Lu, "Strength enhancement of aluminium foams and honeycombs by entrapped air under dynamic loadings," Int. J. Impact Eng., vol. 74, pp. 120-125, Dec. 2014.

[32] S. R. Reid and C. Peng, "Dynamic uniaxial crushing of wood," Int. J. Impact Eng., vol. 19, no. 5-6, pp. 531-570, May 1997.

[33] P. J. Tan, S. R. Reid, J. J. Harrigan, Z. Zou, and S. Li, "Dynamic compressive strength properties of aluminium foams. Part II-'shock' theory and comparison with experimental data and numerical models,” J. Mech. Phys. Solids, vol. 53, no. 10, pp. 2206-2230, Oct. 2005.

[34] S. R. Reid and T. Y. Reddy, "Axial crushing of foam-filled tapered sheet metal tubes," Int. J. Mech. Sci., vol. 28, no. 10, pp. 643-656, Jan. 1986.

[35] S. R. Reid, T. Y. Reddy, and M. D. Gray, "Static and dynamic axial crushing of foam-filled sheet metal tubes," Int. J. Mech. Sci., vol. 28, no. 5, pp. 295-322, Jan. 1986.

[36] A. G. Hanssen, M. Langseth, and O. S. Hopperstad, "Static and dynamic crushing of circular aluminium extrusions with aluminium foam filler," Int. J. Impact Eng., vol. 24, no. 5, pp. 475507, Apr. 2000.

[37] S. P. Santosa, T. Wierzbicki, A. G. Hanssen, and M. Langseth, "Experimental and numerical studies of foam-filled sections," Int. J. Impact Eng., vol. 24, no. 5, pp. 509-534, May 2000.

[38] M. Seitzberger, F. G. Rammerstorfer, R. Gradinger, H. P. Degischer, M. Blaimschein, and C. Walch, "Experimental studies on the quasi-static axial crushing of steel columns filled with aluminium foam," Int. J. Solids Struct., vol. 37, no. 30, pp. 4125-4147, Jul. 2000.

[39] H. R. Zarei and M. Kröger, "Optimization of the foam-filled aluminum tubes for crush box application,” Thin-Walled Struct., vol. 46, no. 2, pp. 214-221, Feb. 2008.

[40] T. Børvik, O. S. Hopperstad, a Reyes, M. Langseth, G. Solomos, and T. Dyngeland, "Empty and foam-filled circular aluminium tubes subjected to axial and oblique quasistatic loading," Int. J. Crashworthiness, vol. 8, no. 5, pp. 481-494, Jan. 2003.

[41] H. Kavi, A. K. Toksoy, and M. Guden, "Predicting energy absorption in a foam-filled thinwalled aluminum tube based on experimentally determined strengthening coefficient," Mater. Des., vol. 27, no. 4, pp. 263-269, Jan. 2006.

[42] A. K. Toksoy and M. Güden, "The strengthening effect of polystyrene foam filling in aluminum thin-walled cylindrical tubes," Thin-Walled Struct., vol. 43, no. 2, pp. 333-350, Feb. 2005.

[43] W. Yan, E. Durif, Y. Yamada, and C. Wen, "Crushing Simulation of Foam-Filled Aluminium Tubes,” Mater. Trans., vol. 48, no. 7, pp. 1901-1906, Jun. 2007. 
[44] L. Mirfendereski, M. Salimi, and S. Ziaei-Rad, "Parametric study and numerical analysis of empty and foam-filled thin-walled tubes under static and dynamic loadings," Int. J. Mech. Sci., vol. 50, no. 6, pp. 1042-1057, Jun. 2008.

[45] Z. Ahmad, D. P. P. Thambiratnam, and A. C. C. C. C. Tan, "Dynamic energy absorption characteristics of foam-filled conical tubes under oblique impact loading," Int. J. Impact Eng., vol. 37, no. 5, pp. 475-488, May 2010.

[46] Z. Ahmad and D. P. Thambiratnam, "Dynamic computer simulation and energy absorption of foam-filled conical tubes under axial impact loading," Comput. Struct., vol. 87, no. 3-4, pp. 186-197, Feb. 2009.

[47] Z. Ahmad and D. P. Thambiratnam, "Crushing response of foam-filled conical tubes under quasi-static axial loading," Mater. Des., vol. 30, no. 7, pp. 2393-2403, Aug. 2009.

[48] W. Chen, "Experimental and numerical study on bending collapse of aluminum foam-filled hat profiles," Int. J. Solids Struct., vol. 38, no. 44-45, pp. 7919-7944, Nov. 2001.

[49] H.-W. Song, Z.-J. Fan, G. Yu, Q.-C. Wang, and A. Tobota, "Partition energy absorption of axially crushed aluminum foam-filled hat sections," Int. J. Solids Struct., vol. 42, no. 9-10, pp. 2575-2600, May 2005.

[50] W. Altenhof, A.-M. Harte, and R. Turchi, "Experimental and numerical compressive testing of aluminum foam filled mild steel tubular hat sections," in 7th International LS-DYNA Users Conference, 2002, no. 3, pp. 19-28.

[51] P. H. Thornton, "Energy Absorption by Foam Filled Structures," in SAE Technical Paper 800081, 1980.

[52] B. E. Lampinen and R. A. Jeryan, "Effectiveness of Polyurethane Foam in Energy Absorbing Structures," in SAE Technical Paper 820494, 1982.

[53] J. Banhart, "Manufacture, characterisation and application of cellular metals and metal foams," Prog. Mater. Sci., vol. 46, no. 6, pp. 559-632, Jan. 2001.

[54] A. G. Hanssen, O. S. S. Hopperstad, and M. Langseth, "Design of aluminium foam-filled crash boxes of square and circular cross-sections," Int. J. Crashworthiness, vol. 6, no. 2, pp. 177188, Jan. 2001.

[55] M. M. Abedi, A. Niknejad, G. H. Liaghat, and M. Zamani Nejad, "Foam-Filled Grooved Tubes with Circular Cross Section Under Axial Compression: An Experimental Study," Iran. J. Sci. Technol. Trans. Mech. Eng., vol. 42, no. 4, pp. 401-413, Dec. 2018.

[56] A. Niknejad, M. M. Abedi, G. H. Liaghat, and M. Zamani Nejad, "Foam-Filled Grooved Tubes with Circular Cross-Section Under Axial Compression: A Theoretical Analysis," Iran. J. Sci. Technol. Trans. Mech. Eng., vol. 40, no. 3, pp. 155-167, Sep. 2016.

[57] S. Asavavisithchai, D. Slater, and A. R. Kennedy, "Effect of tube length on the bucking mode and energy absorption of Al foam-filled tubes," J. Mater. Sci., vol. 39, no. 24, pp. 7395-7396, Dec. 2004.

[58] N. Onsalung, C. Thinvongpituk, and K. Painthong, "The Influence of Foam Density on Specific Energy Absorption of Rectangular Steel Tubes," Energy Res. J., vol. 1, no. 2, pp. 135-140, 2010.

[59] M. Seitzberger, F. G. Rammerstorfer, H. P. Degischer, and R. Gradinger, "Crushing of axially compressed steel tubes filled with aluminium foam," Acta Mech., vol. 125, no. 1-4, pp. 93105, Mar. 1997. 
[60] X. Zhang and G. Cheng, "A comparative study of energy absorption characteristics of foamfilled and multi-cell square columns," Int. J. Impact Eng., vol. 34, no. 11, pp. 1739-1752, Nov. 2007.

[61] S. Yang and C. Qi, "Multiobjective optimization for empty and foam-filled square columns under oblique impact loading," Int. J. Impact Eng., vol. 54, pp. 177-191, Apr. 2013.

[62] C. Qi, S. Yang, and F. Dong, "Crushing analysis and multiobjective crashworthiness optimization of tapered square tubes under oblique impact loading," Thin-Walled Struct., vol. 59, pp. 103-119, Oct. 2012.

[63] A. Reyes, O. S. Hopperstad, and M. Langseth, "Aluminum foam-filled extrusions subjected to oblique loading: experimental and numerical study," Int. J. Solids Struct., vol. 41, no. 5-6, pp. 1645-1675, Mar. 2004.

[64] S. Shahbeyk, A. Vafai, and N. Petrinic, "Axial crushing of metal foam-filled square columns: Foam density distribution and impactor inclination effects," Thin-Walled Struct., vol. 43, no. 12, pp. 1818-1830, Dec. 2005.

[65] J. Shen, G. Lu, D. Ruan, and C. Chiang Seah, "Lateral plastic collapse of sandwich tubes with metal foam core," Int. J. Mech. Sci., vol. 91, pp. 99-109, Feb. 2015.

[66] A. Niknejad, S. A. Elahi, and G. H. Liaghat, "Experimental investigation on the lateral compression in the foam-filled circular tubes," Mater. Des., vol. 36, pp. 24-34, Apr. 2012.

[67] A. Niknejad and D. M. Rahmani, "Experimental and theoretical study of the lateral compression process on the empty and foam-filled hexagonal columns," Mater. Des., vol. 53, pp. 250-261, Jan. 2014.

[68] Z. Fan, J. Shen, and G. Lu, "Investigation of lateral crushing of sandwich tubes," Procedia Eng., vol. 14, pp. 442-449, 2011.

[69] Z. Fan, J. Shen, G. Lu, and D. Ruan, "Dynamic lateral crushing of empty and sandwich tubes," Int. J. Impact Eng., vol. 53, pp. 3-16, Mar. 2013.

[70] A. Niknejad and P. H. H. Orojloo, "A novel nested system of tubes with special cross-section as the energy absorber," Thin-Walled Struct., vol. 100, pp. 113-123, Mar. 2016.

[71] H. R. Zarei and M. Kröger, "Bending behavior of empty and foam-filled beams: Structural optimization," Int. J. Impact Eng., vol. 35, no. 6, pp. 521-529, Jun. 2008.

[72] S. Santosa and T. Wierzbicki, "Effect of an ultralight metal filler on the bending collapse behavior of thin-walled prismatic columns," Int. J. Mech. Sci., vol. 41, no. 8, pp. 995-1019, Aug. 1999.

[73] Z. Li, Z. Zheng, J. Yu, and L. Guo, "Crashworthiness of foam-filled thin-walled circular tubes under dynamic bending,” Mater. Des., vol. 52, pp. 1058-1064, Dec. 2013.

[74] G. Li, Z. Zhang, G. Sun, X. Huang, and Q. Li, "Comparison of functionally-graded structures under multiple loading angles,” Thin-Walled Struct., vol. 94, pp. 334-347, Sep. 2015.

[75] H. Yin, G. Wen, X. Wu, Q. Qing, and S. Hou, "Crashworthiness design of functionally graded foam-filled multi-cell thin-walled structures," Thin-Walled Struct., vol. 85, pp. 142-155, Dec. 2014.

[76] G. Sun, G. Li, S. Hou, S. Zhou, W. Li, and Q. Li, "Crashworthiness design for functionally graded foam-filled thin-walled structures," Mater. Sci. Eng. A, vol. 527, no. 7-8, pp. 19111919, Mar. 2010. 
[77] H. Yin, G. Wen, H. Fang, Q. Qing, X. Kong, J. Xiao, and Z. Liu, "Multiobjective crashworthiness optimization design of functionally graded foam-filled tapered tube based on dynamic ensemble metamodel," Mater. Des., vol. 55, pp. 747-757, Mar. 2014.

[78] M. S. Attia, S. A. Meguid, and H. Nouraei, "Nonlinear finite element analysis of the crush behaviour of functionally graded foam-filled columns," Finite Elem. Anal. Des., vol. 61, pp. 50-59, Nov. 2012.

[79] Y. zhang, M. Lu, G. Sun, G. Li, and Q. Li, "On functionally graded composite structures for crashworthiness," Compos. Struct., vol. 132, pp. 393-405, Nov. 2015.

[80] J. Fang, Y. Gao, G. Sun, Y. Zhang, and Q. Li, "Parametric analysis and multiobjective optimization for functionally graded foam-filled thin-wall tube under lateral impact," Comput. Mater. Sci., vol. 90, pp. 265-275, Jul. 2014.

[81] G. Sun, E. Wang, H. Wang, Z. Xiao, and Q. Li, "Low-velocity impact behaviour of sandwich panels with homogeneous and stepwise graded foam cores," Mater. Des., vol. 160, pp. 11171136, Dec. 2018.

[82] S. Mohsenizadeh, R. Alipour, M. Shokri Rad, A. Farokhi Nejad, and Z. Ahmad, "Crashworthiness assessment of auxetic foam-filled tube under quasi-static axial loading," Mater. Des., vol. 88, pp. 258-268, Dec. 2015.

[83] H. R. Zarei and M. Kröger, "Crashworthiness optimization of empty and filled aluminum crash boxes," Int. J. Crashworthiness, vol. 12, no. 3, pp. 255-264, Sep. 2007.

[84] G. Sun, X. Song, S. Baek, and Q. Li, "Robust optimization of foam-filled thin-walled structure based on sequential Kriging metamodel," Struct. Multidiscip. Optim., vol. 49, no. 6, pp. 897913, 2014.

[85] Y. Zhang, G. Sun, G. Li, Z. Luo, and Q. Li, "Optimization of foam-filled bitubal structures for crashworthiness criteria," Mater. Des., vol. 38, pp. 99-109, Jun. 2012.

[86] X. An, Y. Gao, J. Fang, G. Sun, and Q. Li, "Crashworthiness design for foam-filled thinwalled structures with functionally lateral graded thickness sheets," Thin-Walled Struct., vol. 91, pp. 63-71, Jun. 2015.

[87] J. Fang, Y. Gao, X. An, G. Sun, J. Chen, and Q. Li, "Design of transversely-graded foam and wall thickness structures for crashworthiness criteria," Compos. Part B Eng., vol. 92, pp. 338349, May 2016.

[88] K. Hitti, "Direct numerical simulation of complex Representative Volume Elements (RVEs): Generation, Resolution and Homogenization," Dec. 2011.

[89] R. D. Hussein, D. Ruan, G. Lu, S. Guillow, and J. W. Yoon, "Crushing response of square aluminium tubes filled with polyurethane foam and aluminium honeycomb," Thin-Walled Struct., vol. 110, no. June 2016, pp. 140-154, 2017.

[90] Z. Li, J. Yu, and L. Guo, "Deformation and energy absorption of aluminum foam-filled tubes subjected to oblique loading," Int. J. Mech. Sci., vol. 54, no. 1, pp. 48-56, 2012.

[91] A. G. Hanssen, M. Langseth, and O. S. Hopperstad, "Optimum design for energy absorption of square aluminium columns with aluminium foam filler," Int. J. Mech. Sci., vol. 43, no. 1, pp. 153-176, Jan. 2001. 


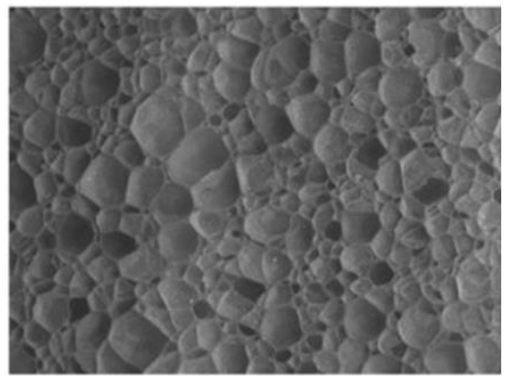

(a)

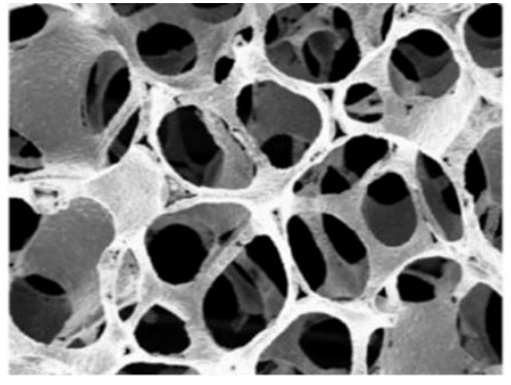

(b)

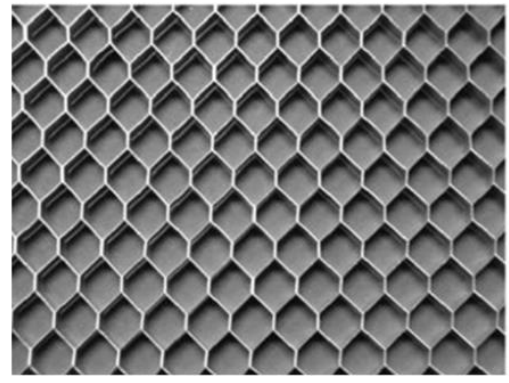

(c)

Figure 1: Cell structure of foam material (a) closed cell- (b) open cell- (c) honeycomb [88] 


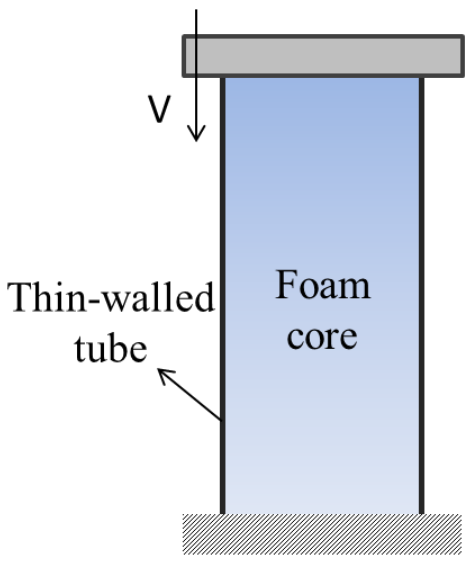

(a)

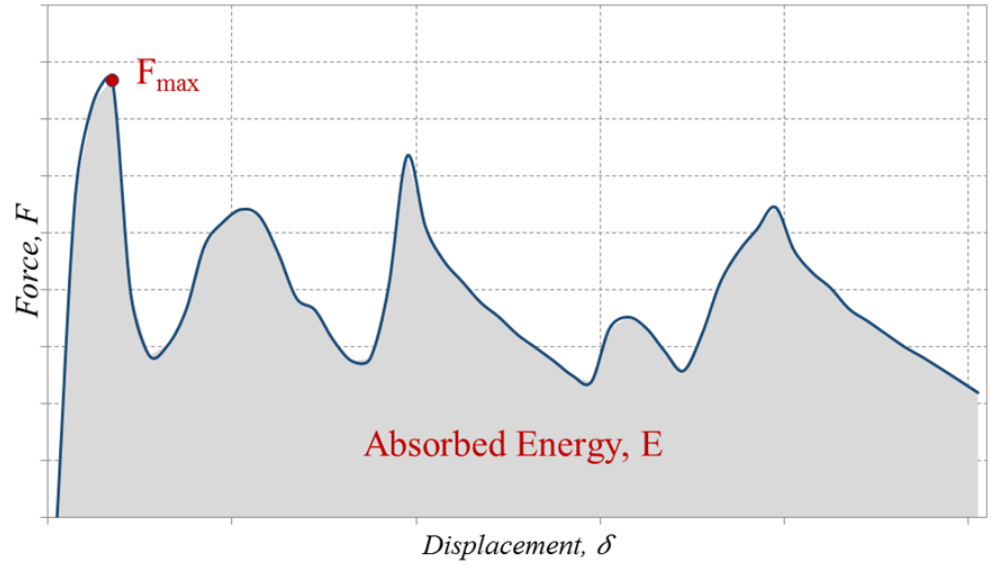

(b)

Figure 2: Crashworthiness metrics (a) schematic of crushing test of a foam-filled structure (b) typical crush forcedisplacement response 


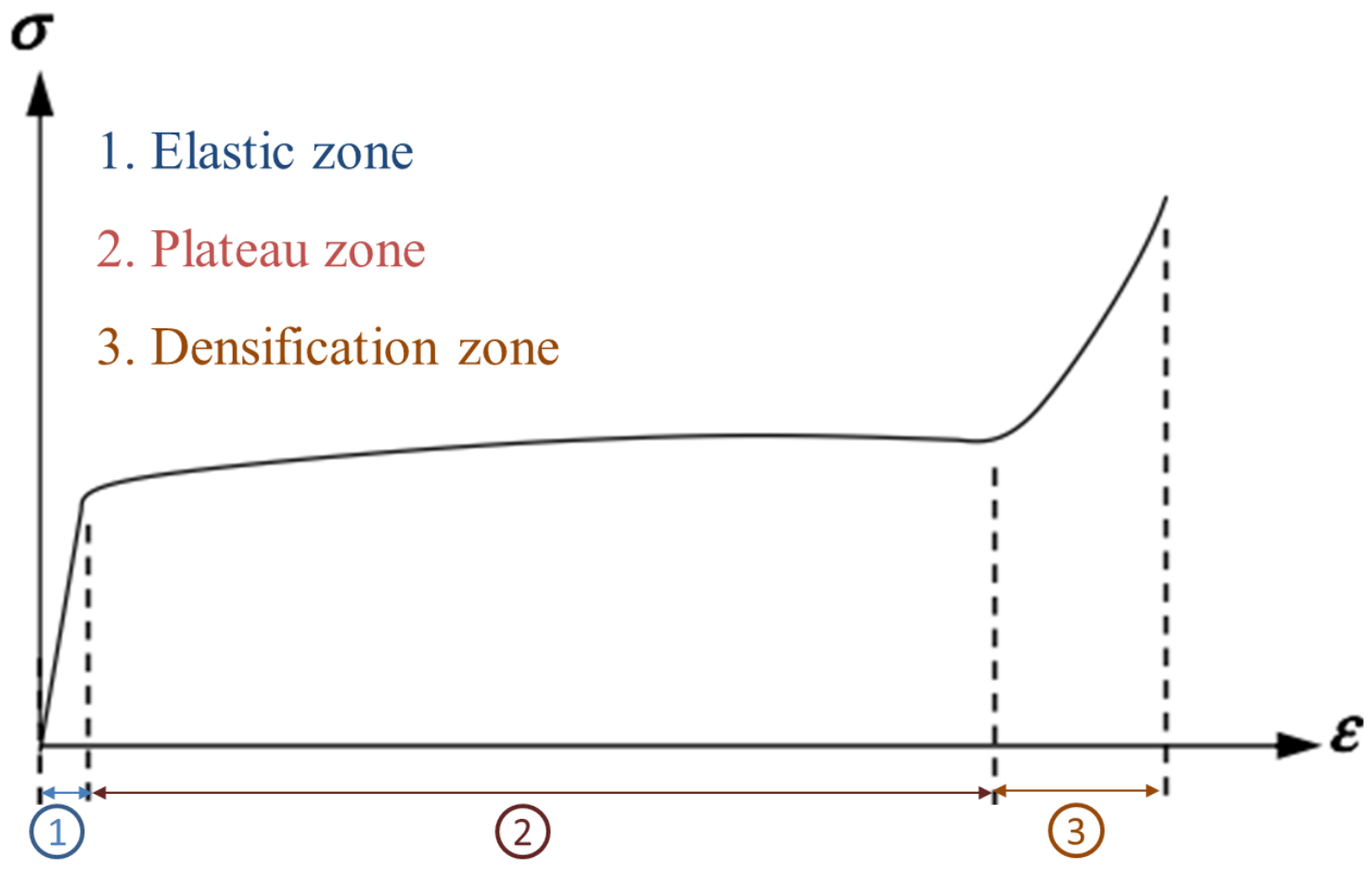

Figure 3: A typical compressive stress-strain curve for foam materials 


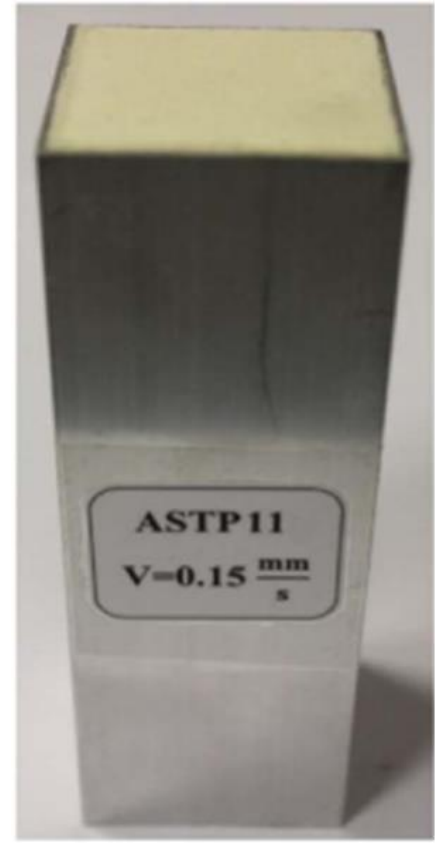

(a)

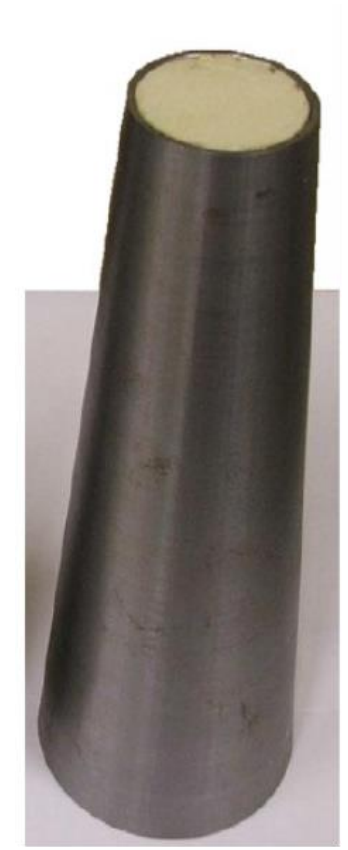

(b)

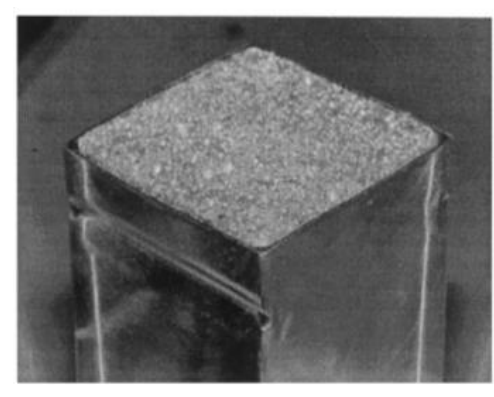

(c)

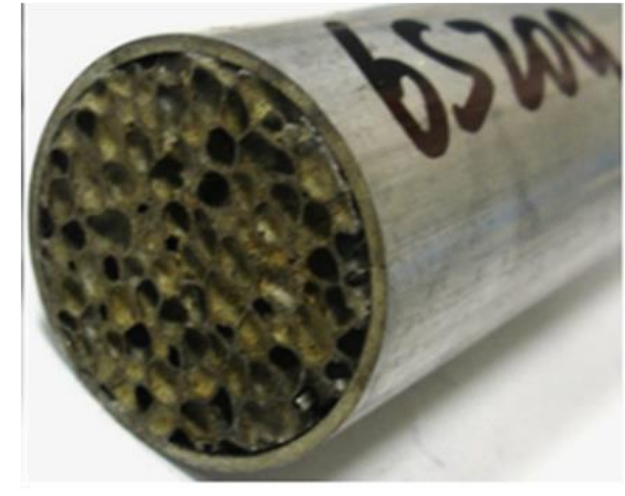

(d)

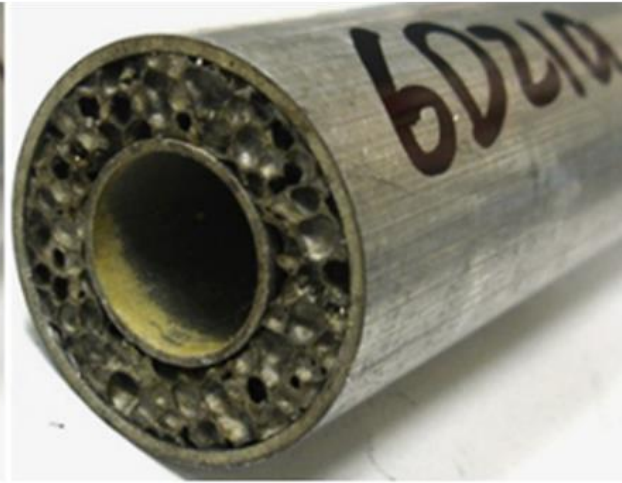

(e)

Figure 4: Typical foam-filled tubes a) Polyurethane foam-filled square tube [89]- b) Polyurethane foam-filled frusta [45]- c) Al foam-filled rectangle tube [36]-d) Al foam-filled circular tubes[90]-e) Al foam-filled bi-tubular circular tubes[90]. 


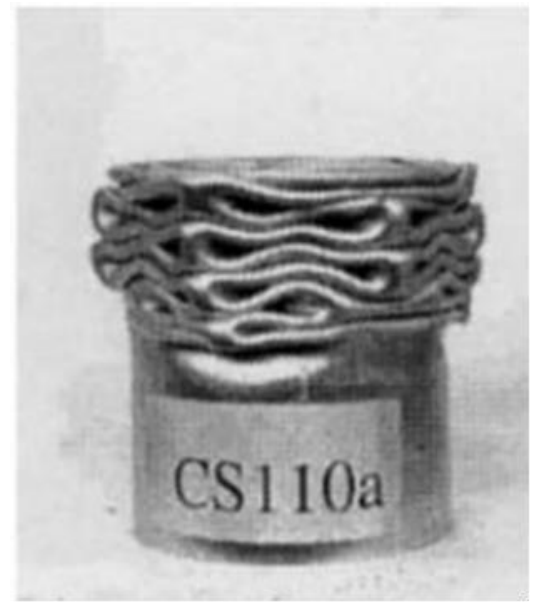

$a$

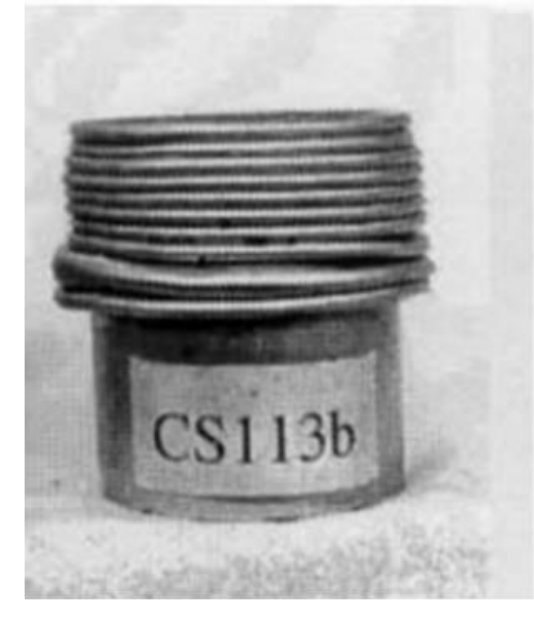

b

Figure 5: Deformation modes of (a) empty- (b) foam-filled $\left(\rho=0.35 \mathrm{~g} / \mathrm{cm}^{3}\right)$ circular tubes [36] 


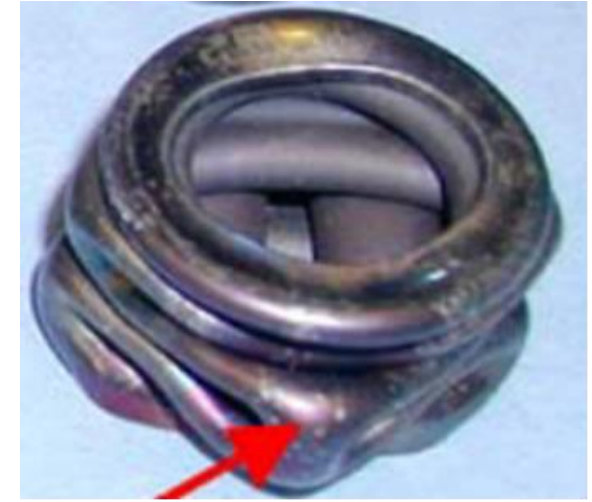

$a$

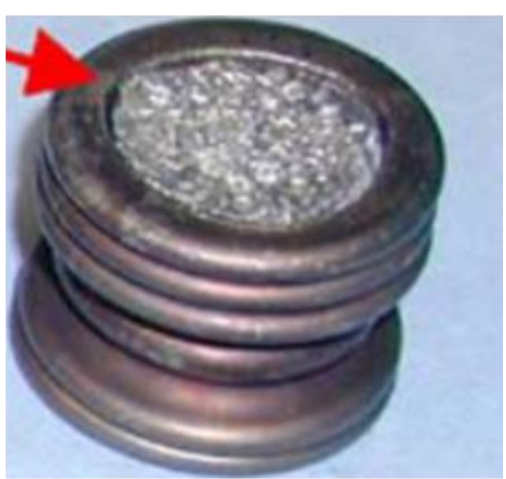

$b$

Figure 6: Diamond and concertina deformation modes of (a) empty- (b) foam-filled long tubes [57] 


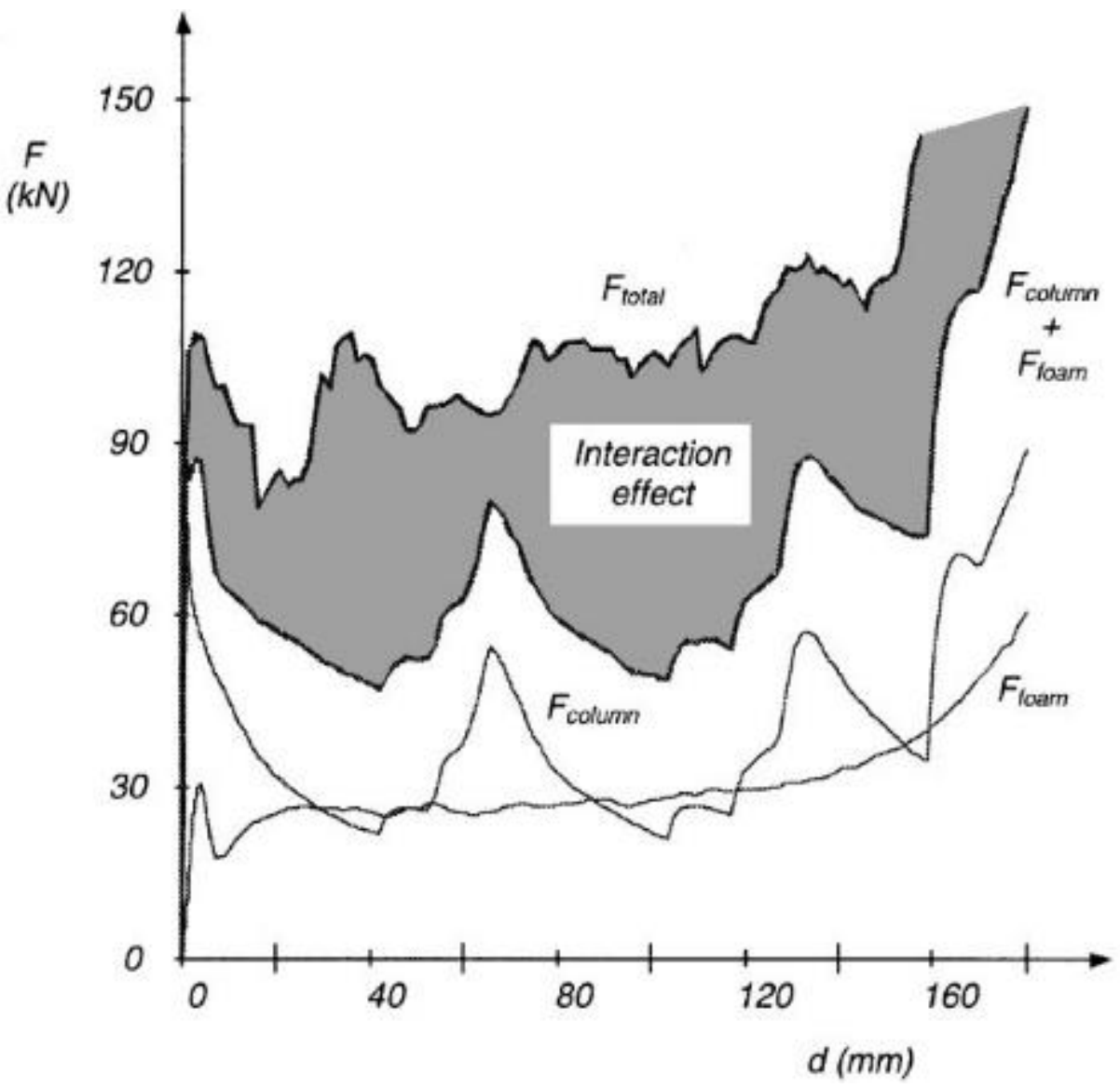

Figure 7:Illustration of interaction effects in foam-filled structures [91] 


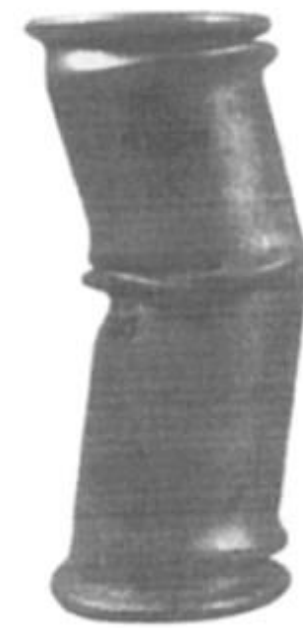

Figure 8: Global bending in axially crushed foam filled circular tubes [59] 


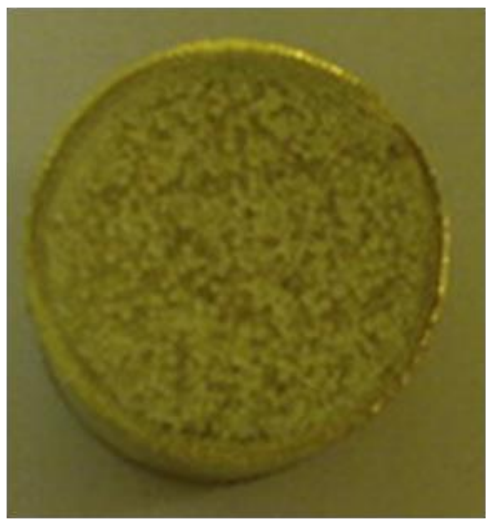

$a$

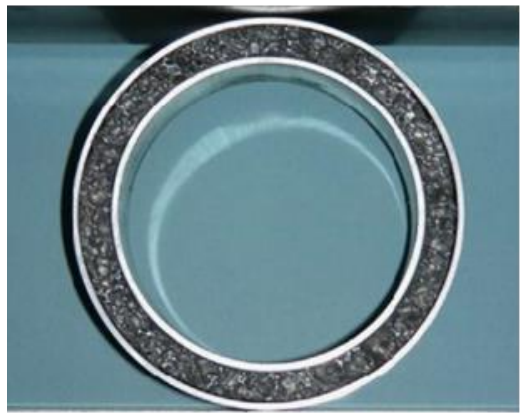

C

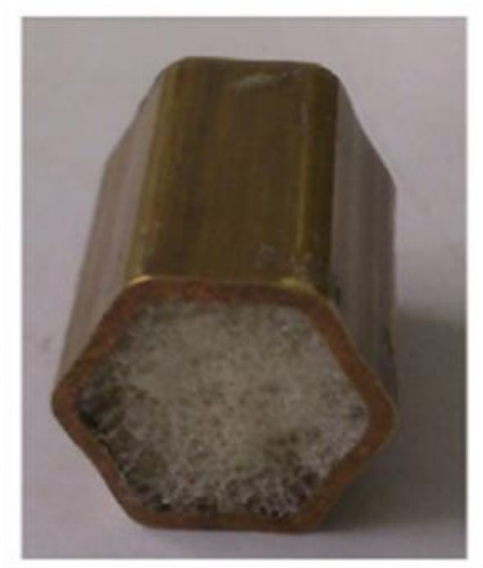

b

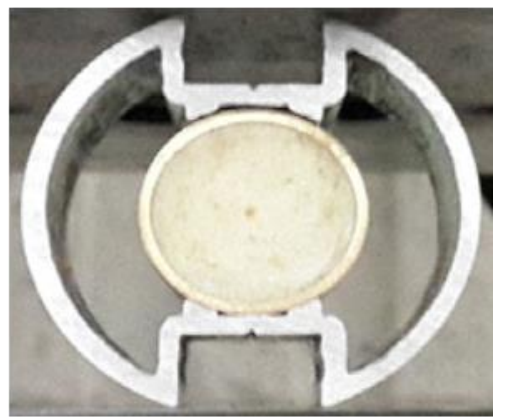

$d$

Figure 9: Laterally crushed foam filled tubes; (a) polyurethane foam-filled Circular tube [66] - (b) polyurethane

Foam-filled hexagonal tube [67]- (c) Sandwich tube with ALPORAS [65]- (d) nested foam-filled tube [70] 


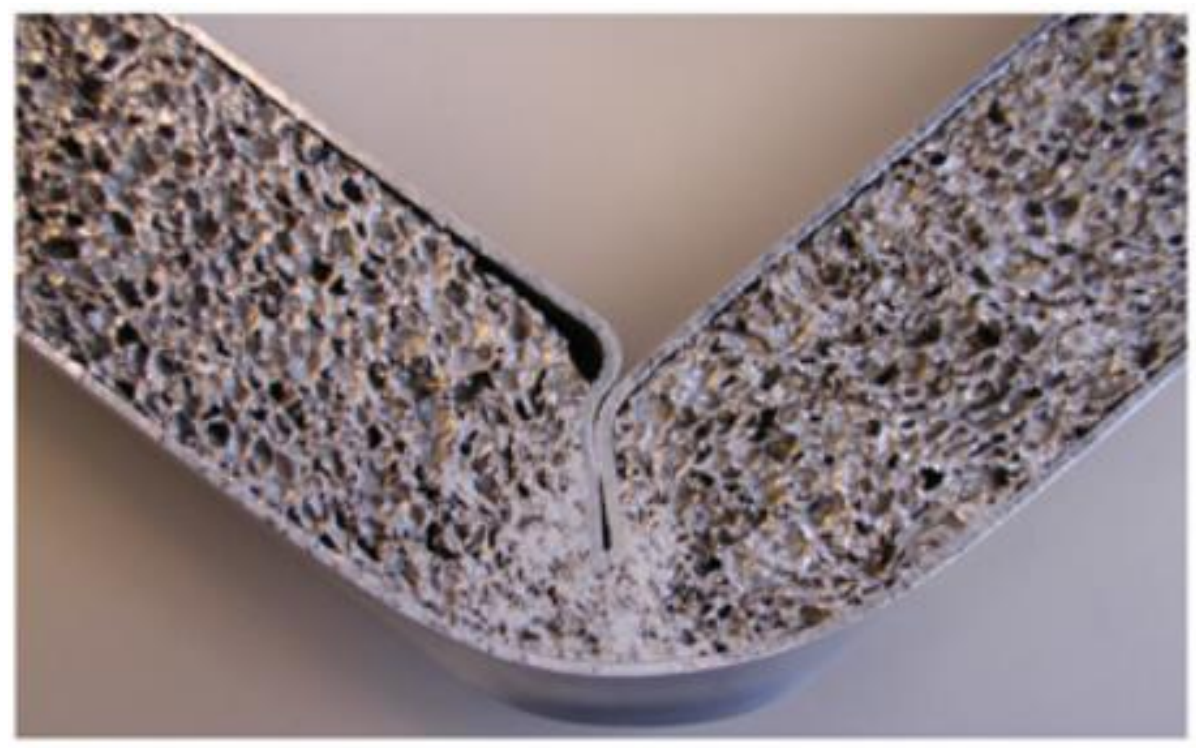

Figure 10: Deformation mode of foam-filled tubes under bending loading [71] 


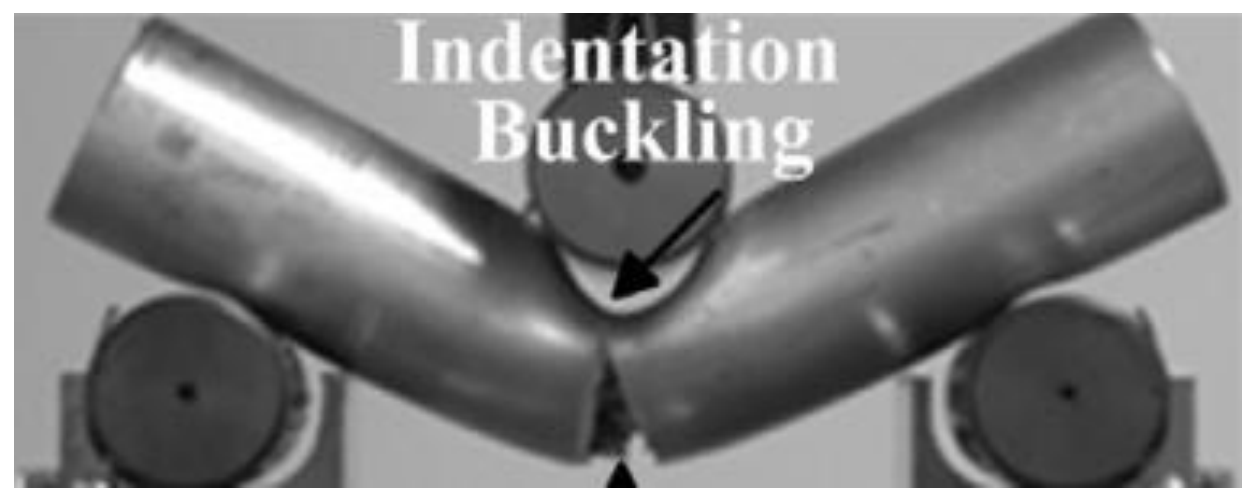

Figure 11: Tensile failure in foam-filled tube under bending loading [13] 
a

Loading Platen

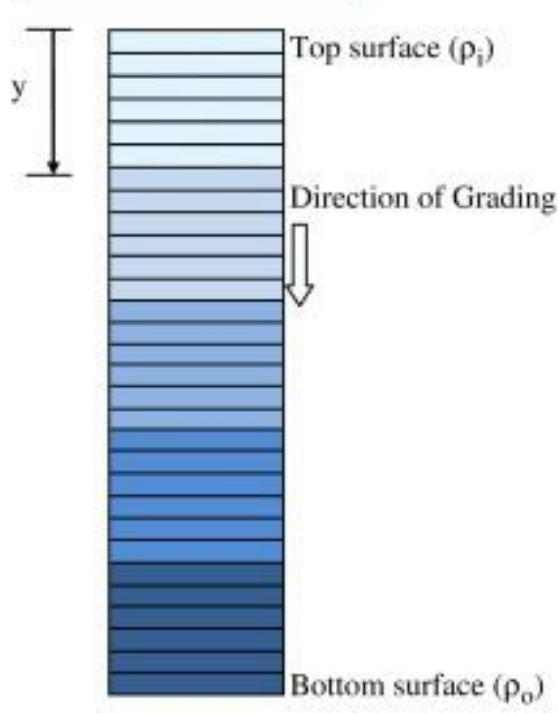

b

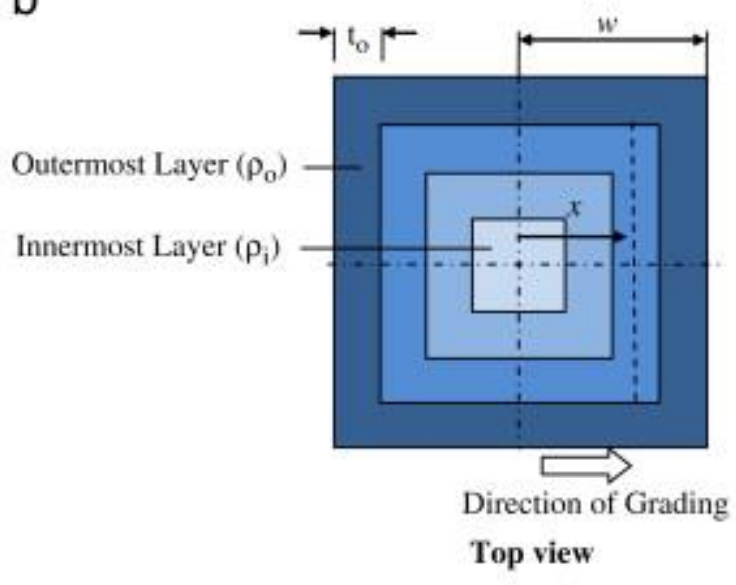

Figure 12: Density grading patterns, (a) Axial, and (b) lateral [78] 